\title{
Lymphocyte as A Predictive Marker for Seronegativity of COVID-19
}

\author{
Irfan Ali ${ }^{1}$, Muhammad Khuram Sattar ${ }^{2}$, Muhammad Qasim ${ }^{3}$, Fakhra Saba Zeb ${ }^{4}$, Muhammad \\ Fahad Ali ${ }^{5}$, Hassan Mumtaz ${ }^{6}$, Shahzaib Ahmad ${ }^{7 *}$, Syeda Ameera Nobia ${ }^{8}$ and Muhammad Ahsan \\ Shafiq $^{9}$
}

${ }^{1}$ Resident Gastroenterology PEMH, Rawalpindi, Pakistan

${ }^{2,3}$ Medical Officer, Benazir Bhutto Hospital, Rawalpindi, Pakistan

${ }^{4,5}$ Senior Registrar Medicine, Medical Specialist KRL Hospital, Pakistan

${ }^{6}$ House Surgeon KRL Hospital \& Former Internee Guys St Thomas Hospital London GBR, UK

${ }^{7}$ King Edward Medical University, Pakistan

${ }^{8}$ Resident Surgeon KRL Hospital, Pakistan

${ }^{9}$ Resident Physician Holy Family Hospital, Pakistan

*Corresponding author: Shahzaib Ahmad, King Edward Medical University Lahore, Pakistan

\section{ARTICLE INFO}

Received: 幽 December 08, 2020

Published: 蔧 December 16, 2020

Citation: Irfan A, Muhammad Khuram S, Muhammad Q, Fakhra Saba Z, Muhammad Fahad A, Hassan M, Shahzaib A, et al.. Lymphocyte as A Predictive Marker for Seronegativity of COVID-19. Biomed J Sci \& Tech Res 32(4)-2020. BJSTR. MS.ID.005279.

\section{ABSTRACT}

Background: To use baseline lymphocyte as a predictive marker of covid 19 seronegativity.

Method: In this study, the baseline lymphocyte of every covid patient, diagnosed on basis PCR (nasopharyngeal swab) was done, and they were monitored. All patients in this study are aged between 20 to 84 years, and their PCRs are repeated after 7 days of $1^{\text {st }}$ PCR as per guideline of WHO in April. A sum of 142 patients was observed for over 7 to 35 days.

Result: Lymphocyte count has a co-relation with seronegativity. It has been observed, patient with high or normal lymphocyte count are more likely to have a negative PCR test after 7 days of their initial test provided, they are asymptomatic, while those with low lymphocyte count are likely to have a negative conversion of their test in 14 to 35 days, depend on age and comorbid.

\section{Introduction}

In the month of December 2019, in Wuhan Province of China, multiple cases of pneumonia with an unknown origin were reported. By PCR and bronchoalveolar lavage studies, it was confirmed that the causative microorganism belongs to virus family and name coronavirus/Noval Covid-19 (SARS-COV-2) AND DISEASES NAMED AS covid-19 [1]. The virus got international attention as it spreads to Japan, Korea, Iran, India and New Zealand. America and Italy were badly affected by this virus, and the mortality rate went beyond 8\%. In March WHO declared Covid as the pandemic of 20 th century. Pakistan is badly hit by covid 19 , and in the first week of June the total number of confirmed cases was above 150 thousand and deaths were around 3000. While the world census is above 8 million total confirmed cases with 0.5 million deaths.
Lymphocytes play a pivotal role in maintaining our immune system. The alteration in the total lymphocyte count after viral infection indicates a potential association between lymphocyte and viral pathogenic mechanism [2,3]. The studies Conducted after COVID 19 declared as a pandemic, indicated showed a low lymphocyte count, but its impact on seronegativity of COVID is still unknown [4]. I this article we aimed to establish a role of lymphocyte count and number of days taken for seroconversion of COVID 19.

\section{Patients and Methods}

It is a longitudinal study in which a total of 142 patients have been monitored for 7 to 35 days admitted in a field hospital in Rawalpindi district. The research is conducted for 40 days from 
the $20^{\text {th }}$ of April to the $30^{\text {th }}$ of May. All patients were male, and age ranges from 20 to 84 years. All patients were confirmed covid case diagnosed on nasopharyngeal sample PCR. The patients were further classified into two groups, those who stayed less than 8 days and those who stayed more than 8 days. Patient's lymphocyte counts were monitored at the time of admission, and their outcome is monitored.

\section{Results}

142 patients of COVID-19 included in this study. The median age was years, and all were male. Most of the patients were asymptomatic or had mild symptoms of Covid. Three of the patients died during the treatment. Their stay in the hospital while the rest of 139 was fully recovered. 07 of them were shifted to ICU based on symptoms and chest X-ray findings. It is seen that patients with low lymphocyte count have taken more than 2 weeks to have their PCR negative, while those with normal or high lymphocyte count have cleared the virus in a time span of a week (Tables $1 \& 2$ ). The mean age of patients was 37 years, while the average stays of patients 11 days with SD deviation _5.6. In addition, the mean lymphocytic count of 142 patients was $25 \%$ with SD 12.5, while the absolute lymphocytic count was 1.80 with SD 1.3. We analyze the level of lymphocytes and relate it with the number of days patients spent in a field hospital and days they have taken for seroconversion. 61 out of 142 patients have stayed more than 8 days, and their PCR was negative after more than 14 days. All of them have low lymphocyte count at the time of admission.

Table 1: Correlations.

\begin{tabular}{|c|c|c|c|c|c|}
\hline & & $\begin{array}{c}\text { Number of days at } \\
\text { hospital }\end{array}$ & White cell count & $\begin{array}{c}\text { Absolute lymphocytic } \\
\text { count }\end{array}$ & $\begin{array}{l}\text { Percentage of } \\
\text { lymphocyte }\end{array}$ \\
\hline \multirow{3}{*}{$\begin{array}{c}\text { Number of days at } \\
\text { hospital }\end{array}$} & Pearson Correlation & 1 & $-.176^{*}$ & $-.530^{* *}$ & $-.685^{* *}$ \\
\hline & Sig. (2-tailed) & & .039 & .000 & .000 \\
\hline & $\mathrm{N}$ & 139 & 139 & 139 & 138 \\
\hline \multirow{3}{*}{ White Cell Count } & Pearson Correlation & $-.176^{*}$ & 1 & $.548^{* *}$ & .152 \\
\hline & Sig. (2-tailed) & .039 & & .000 & .072 \\
\hline & $\mathrm{N}$ & 139 & 142 & 142 & 141 \\
\hline \multirow{3}{*}{$\begin{array}{l}\text { Absolute lymphocytic } \\
\text { count }\end{array}$} & Pearson Correlation & $-.530 * *$ & $.548^{* *}$ & 1 & $.782^{* *}$ \\
\hline & Sig. (2-tailed) & .000 & .000 & & .000 \\
\hline & $\mathrm{N}$ & 139 & 142 & 142 & 141 \\
\hline \multirow{3}{*}{$\begin{array}{l}\text { Percentage of } \\
\text { lymphocyte }\end{array}$} & Pearson Correlation & $-.685 * *$ & .152 & $.782^{* *}$ & 1 \\
\hline & Sig. (2-tailed) & .000 & .072 & .000 & \\
\hline & $\mathrm{N}$ & 138 & 141 & 141 & 141 \\
\hline
\end{tabular}

*Correlation is significant at the 0.05 level (2-tailed).

**Correlation is significant at the 0.01 level (2-tailed).

Table 2: Descriptive Statistics.

\begin{tabular}{|c|c|c|c|c|c|c|}
\hline & N & Range & Minimum & Maximum & Mean & Std. Deviation \\
\hline age & 142 & 53 & 16 & 69 & 37.11 & 10.473 \\
\hline percentage of lymphocyte & 141 & 55 & 2 & 57 & 25.30 & 12.513 \\
\hline white cell count & 142 & 23 & 1 & 24 & 7.46 & 3.620 \\
\hline Absolute lymphocytic count & 142 & 6.58 & .02 & 6.60 & 1.8675 & 1.31747 \\
\hline Number of days at hospital & 139 & 28 & 8 & 36 & 11.75 & 5.681 \\
\hline Valid N (listwise) & 138 & & & & & \\
\hline
\end{tabular}

\section{Discussion}

Lymphocytes play an important role in our body defense system. Lymphocyte count is an index of disease progression and severity. Differential lymphocyte count is often employed to diagnose certain diseases [5,6]. Acute disease conditions are associated with raised macrophages and neutrophil count. In contrast, chronicity is associated with the prevalence of lymphocyte numbers. A rise in eosinophil count is frequently associated with underlying parasitic and allergic aetiology $[7,8]$. Similarly, infection with Severe Acute Respiratory Syndrome Virus-2 (SARS-CoV-2) is associated with a change in leukocyte count [9]. A general trend seen in most of the COVID patients is the raise in lymphocyte count [10]. Looking at the usual trend of disease severity, most of the patients develop a milder form of the disease with benign signs and symptoms. Many of the diagnosed patients tested with Rt-PCR were asymptomatic. This is attributed to natural immunity of the host to SARS-CoV-2 [11]. 
Similarly, low lymphocyte count against viral infection is associated with poor defense against the invading pathogen [12]. A number of research studies have been conducted on the role of baseline lymphocyte as a marker of severity, but none of them to date have focused on seroconversion. Seroconversion forms a valuable basis for prediction of host response against SARS-CoV-2 [13]. Low lymphocyte count is investigated for its possible association with severe disease outcomes.

As $98 \%$ of COVID patients have a mild course of illness. Out of several ways to label a patient to have a milder course of the disease, the number of hospital days or number of quarantine days is one of the crucial factors. Lymphocyte count forms a baseline marker which can predict the number of days [14]. Recently, a study was conducted in Hong Kong, in which the patterns of lymphocyte counts were discussed in critically ill patients [15].

This study demonstrated that out of 142 patients, 3 individuals who died had very low lymphocyte count, and those who were shifted to the intensive care unit had similar findings on Complete Blood Count (CBC). Several systematic review and meta-analysis studies support the notion of the study. A review study, including 24 clinical trials with a total of 3099 patient showed a significant relationship of low lymphocyte count with poor outcome of COVID patients. In comparison, the age of the patient is the predictive factor of severe outcome in patients with poor outcomes [16]. Moreover low lymphocytes are associated with greater odds of COVID patients leading to an Intensive Care Unit (ICU) admission. ICU admission is characterized by poor compliance to usual treatment strategies, and the patient is shifted to advanced therapies to save the life of the patient. Lymphopenia is an established predictor of ICU admission. Low blood lymphocyte counts among COVID patients reflect disease severity. Acute organ failure and Acute Kidney Injury (AKI) frequently occur in COVID patients with low lymphocyte counts [17].

\section{Conclusion}

The finding of studies showed a clear association between lymphocyte count and seroconversion, as those patients with low lymphocyte count have a longer duration of stay and adverse outcomes, and 7 of them shifted to ICU and 3 of them died. There are a few other factors that contributed to ICU and deaths, but lymphocyte is the only marker that determines seroconversion.

\section{References}

1. ZhuN,ZhangD,WangW,XingWL,BoY,etal.(2020)Anovelcoronavirusfrom Patients with pneumonia in China, 2019. N Engl J Med 382: 727-733.
2. Chan MH, Wong VW, Wong CK, PKS Chan, Chung MC, et al. (2004) Serum LD1 isoenzyme and blood lymphocyte subsets as prognostic indicators for the severe acute respiratory syndrome. J Intern Med 255(4): 512 518.

3. Cui W, Fan Y, Wu W, Zhang F, Wang JY, et al. (2003) Expression of lymphocytes and lymphocyte subsets in patients with severe Acute respiratory syndrome. Clin Infect Dis 37(6): 857-859.

4. Per NC, Shrestha N, Rahman MS, R Zaki, Z Tan, et al. (2020) The SARS, MERS and novel coronavirus (COVID-19) epidemics, the newest and biggest global health threats: What lessons have we learned? Int J Epidemiol 49(3): 717-726.

5. Chen N, Min Z, X Dong, J Qu, F Gong, et al. (2020) Epidemiological and clinical characteristics of 99 cases of 2019 novel Coronavirus pneumonia in Wuhan, China: a descriptive study. Lancet 395(10223): 507-513.

6. Zhu N, D Zhang, W Wang, X Wang, Bo Y, et al. (2020) A novel coronavirus from patients with pneumonia in China, 2019. N. Engl. J. Med 382: 727733.

7. Wang D, Bo H, C Hu, F Zhu, X Liu, et al. (2020) Clinical characteristics of 138 hospitalized patients with 2019 novel Coronavirus-infected pneumonia in Wuhan, China. JAMA 323(11): 1061-1069.

8. Huang C, Y Wang, X Wang Li, L Ren, J Zhao, et al. (2020) Clinical features of patients infected with 2019 novel coronavirus in Wuhan, China. Lancet 395(10223): 497-506.

9. Liao YC, WG Liang, FW Chen, JH Hsu, JJ Yang, et al. (2002) IL-19 induces production of IL- 6 and TNF-alpha and results in cell Apoptosis through TNF-alpha. J. Immunol 169(8): 4288-4297.

10. Fischer K, Petra H, Simon V, Norbert M, Julia A, et al. (2007) Inhibitory effect of tumour cell-derived lactic acid on human T cells. Blood 109(9): 3812-3819.

11. Zeng Z, Yu H, Chen H, Qi W, Chen L, et al. (2020) Longitudinal changes of inflammatory parameters and their correlation with disease severity and outcomes in patients with COVID-19 from Wuhan, China. Critical Care 24(1): 1-2.

12. Meng LB, Yu ZM, Guo P, QQ Wang, RM Qui, et al. (2018) Neutrophils and neutrophil-lymphocyte ratio: inflammatory markers associated with intimal-Media thickness of atherosclerosis. Thromb Res 170: 45-52.

13. Okugawa Y, Toriyama Y, Yamamoto A, Shigemori T, Ide S, Kitajima T, et al. (2020) Lymphocyte-C-reactive protein ratio as a promising new marker for predicting surgical and Oncological outcomes in colorectal cancer. Ann Surg.

14.Gao Y, Li T, Han M, X Li, D Wu, et al. (2020) Diagnostic utility of clinical laboratory data Determinations for patients with severe COVID-19. J Med Virol 92(7).

15. Liu Z, Long W, Tu M, Chen S, Huang Y, et al. (2020) Lymphocyte subset $(\mathrm{CD} 4+, \mathrm{CD} 8+)$ counts reflect the severity of infection and predict the clinical outcomes in patients with COVID-19. Journal of Infection 81(2): 318-356.

16. Huang I, Pranata R (2020) Lymphopenia in severe coronavirus disease-2019 (COVID-19): systematic review and meta-analysis. Journal of Intensive Care 8(1): 1-10.

17. Wagner J, DuPont A, Larson S, Cash B, Farooq A (2020) Absolute lymphocyte count is a prognostic marker in Covid-19: A retrospective cohort review. International Journal of Laboratory Hematology 42(6): 761-765. 
ISSN: 2574-1241

DOI: 10.26717/BJSTR.2020.32.005279

Shahzaib Ahmad. Biomed J Sci \& Tech Res

(c) (P) This work is licensed under Creative

Submission Link: https://biomedres.us/submit-manuscript.php

$\begin{array}{ll}\text { BIOMEDICAL } & \text { Assets of Publishing with us } \\ \text { RESEARCHES } & \text { - Global archiving of articles } \\ & \text { - Immediate, unrestricted online access } \\ & \text { - Rigorous Peer Review Process } \\ \end{array}$

